\title{
El taller del encuadernador Pedro Martínez en la sociedad madrileña de finales del siglo XVIII y primeros del XIX El caso de la Real Academia de Bellas Artes de San Fernando
}

\author{
Antonio Carpallo Bautista ${ }^{1}$, Yohana Yessica Flores Hernández ${ }^{2}$ y \\ Esther Burgos Bordonau ${ }^{1}$ \\ ${ }^{1}$ Universidad Complutense de Madrid. Facultad de Ciencias de la Documentación, Madrid, España / acarpall@ucm.es I \\ https://orcid.org/oooo-0001-7382-0649 / eburgos@ucm.es | https://orcid.org/oooo-0003-3831-9693 \\ ${ }^{2}$ Ministerio de Justicia, España / amoxtlan@gmail.com | https://orcid.org/oooo-0oo2-1876-4258
}

\begin{abstract}
Resumen
El presente estudio tiene como objetivo principal poner en valor el trabajo realizado por el librero y encuadernador Pedro Martínez, con librería y taller en Madrid desde finales del siglo XVIII hasta la primera década del XIX, en la Real Academia de Bellas Artes de San Fernando, realizado mediante la consulta de los libros de cuentas y legajos del Archivo de la Academia y el análisis in situ de las encuadernaciones reseñadas en la documentación, conociendo así mejor el tipo de encuadernaciones encargadas, sus precios, materiales, destinatarios, ayudando a entender mejor la historia de la propia institución, al gremio de libreros, impresores y encuadernadores madrileños y por consiguiente de la sociedad madrileña de la época.
\end{abstract}

\section{Abstract}

The workshop of the binder Pedro Martínez in the Madrid society of the late eighteenth and early nineteenth century: The case of the Real Academia de Bellas Artes de San Fernando. The aim of this study is to put into value the work done by the bookseller and bookbinder Pedro Martínez, with a bookstore and workshop in Madrid from the end of the eighteenth century until the first decade of the nineteenth century, at the Royal Academy of Fine Arts of San Fernando. This work was made through the consultation of the account books and other files of the Academy Archive and the analysis in situ of the bookbindings outlined in the documentation, thus getting to know better the type of bindings ordered, their prices, materials, recipients, for a better understanding of the history of the institution itself, the guild of booksellers, printers and bookbinders from Madrid and therefore from the society of that time in the city.

\section{Palabras clave}

Edad Moderna Madrid

Real Academia de Bellas Artes de San Fernando Pedro Martínez

Libreros-Encuadernadores
Keywords

Modern Age Madrid

Royal Academy of Fine Arts of San Fernando

Pedro Martínez

Booksellers-Bookbinders 


\section{Introducción ${ }^{1}$}

1. El artículo se enmarca dentro de dos proyectos de investigación: el primero financiado por la Universidad Complutense y el Banco Santander dentro de los proyectos 2016-2017 con el título “Las encuadernaciones de la Real Academia de Bellas Artes de San Fernando: estudio, digitalización, identificación y difusión" (PR26/16-20257); el segundo financiado por el $\mathrm{Mi}$ nisterio de Economía, Industria y Competitividad de España dentro de los proyectos de investigación +D, titulado “La encuadernación española en las Reales Academias: encuadernadores, talleres y tipologías ligatorias (S. XVIII-XX)" (HAR2017-83387-P) (2018-2021).
La ciudad de Madrid acoge a un gran número de libreros, impresores y encuadernadores a mediados del siglo XVIII, siendo la ciudad española más importante en el comercio del libro. Algunos de sus impresores y libreros más relevantes fueron Antonio y Gabriel de Sancha, Joaquín Ibarra, Pedro Joseph Alonso, Francisco Manuel de Mena, varios de ellos Libreros de Cámara del Rey y fundadores de la Compañía General de Impresores y Libreros del Reino en 1763, aunque ya existía para esa fecha la Compañía de Libreros de Madrid o Compañía de Mercaderes de libros de Madrid. Además conocemos la existencia de las hermandades de San Juan ante puerta Latinam (para los impresores) y San Jerónimo (para los libreros), no siendo obligatoria su adscripción, acogiéndose a ellas otros oficios como los encuadernadores.

Muchos de esos libreros e impresores también disponían de talleres de encuadernación como Sancha e Ibarra, algunos de ellos además Encuadernadores de Cámara como señala López Serrano en sus estudios que referenciamos a continuación.

Pero poco sabemos de encuadernadores modestos que trabajaron para las grandes instituciones (Castañeda y Alcover, 1958), como es el caso del artesano Pedro Martínez que realizó, desde 1794 hasta su muerte en 1808, diversos encargos de encuadernaciones para la Real Academia de Bellas Artes de San Fernando, trabajos muchos de ellos sencillos, aunque también encargos para regalar a nobles y reyes, y que nos ayudan a conocer los gustos y necesidades de la biblioteca, en cuanto a los títulos y materias de las obras y de sus encuadernaciones, y de las personas a quienes se regalaban.

Algunos de esos encuadernadores desconocidos están saliendo a la luz gracias a los proyectos que se están llevando a cabo en la actualidad como el artículo donde se recoge información de todos los encuadernadores que trabajaron para la Academia de Bellas Artes, aunque solo incluyen datos muy generales como fechas de sus actividades y algunos datos biográficos, sin entrar en el estudio de las encuadernaciones y trabajos realizados (Flores Hernández y Carpallo Bautista, 2017: 255-263). En otro artículo se ha dado a conocer el trabajo del taller de Sancha para la Real Academia de Bellas Artes (Flores Hernández; Carpallo Bautista y Burgos Bordonau, 2018: 39-62), dato que no se conocía hasta ahora, ya que solo teníamos constancia de que Antonio y su hijo Gabriel habían trabajado como encuadernadores oficiales para la Real Academia Española y la Real Academia de la Historia.

Los estudios realizados sobre la encuadernación española son escasos y más aún si hablamos de la encuadernación en la sociedad madrileña. Solo algunos artículos publicados (Cavestany, 1927), (Capela Martínez, 1963: 121-155), (Carrión Gútiez, 1994: 395-445), (López Castán, 1986: 41-63) y sobre todo los de Matilde López Serrano (1937: 1-13; 1940: 27-38; 1945a: 4-5, 28; 1945b: 1-16; 1945c: 51-72; 1946a: 269-307; 1946b: 391399; 1950: 115-131; 1975) haciendo hincapié en los Encuadernadores de Cámara que trabajaron para la Real Biblioteca.

En la actualidad se están comenzando a estudiar los archivos de otras Reales Academias de Madrid (Historia, Lengua, Medicina, Farmacia, Ciencias Morales y Políticas, Ciencias Exactas, Físicas y Naturales, Jurisprudencia y Legislación), con lo que al finalizar el proyecto se podrán hacer estudios comparativos de talleres, encuadernadores y trabajos realizados.

Las siguientes páginas pretenden dar a conocer a uno de esos encuadernadores modestos, Pedro Martínez, que realizó encuadernaciones austeras en su obrador de Madrid para la Real Academia de Bellas Artes, muchas de ellas para la venta, otras para regalar y también para aumentar el fondo de la Biblioteca. El estudio de los recibos 
encontrados en los libros de cuentas y legajos nos hacen determinar cuáles eran el tipo de encuadernaciones más frecuentes que realizaba, los materiales de recubrimientos, las técnicas de construcción y las estructuras decorativas, tanto en las tapas y lomo preferentemente. También se podrán observar los precios por cada tipo de encuadernación y realizar un inventario de hierros empleados en la ornamentación, lo que ayudará en la identificación, futura en otras instituciones, de encuadernaciones salidas de su taller.

\section{Metodología}

Este trabajo se encuentra dentro de los objetivos previstos de un proyecto de investigación competitivo y de las cláusulas incluidas en el convenio firmado entre la Real Academia de Bellas Artes de San Fernando y el grupo Bibliopegia de la Universidad Complutense de Madrid en 2012 para el estudio de las encuadernaciones de la Biblioteca, Archivo, Museo y Calcografía Nacional.

El estudio comenzó con un inventario de todas las encuadernaciones artísticas de los diferentes departamentos, haciendo un análisis detallado de los materiales empleados, técnicas de construcción, estructura, técnicas y elementos decorativos y estado de conservación, además de identificar los antiguos poseedores y sobre todo los encuadernadores; también se realizó la digitalización de las encuadernaciones inventariadas.

De forma paralela se comenzó con la revisión de los libros de cuentas y legajos del Archivo, con el fin de obtener información sobre los gastos producidos en la Academia, desde su creación, para el pago por las encuadernaciones, teniendo en cuenta que las obras que proceden de legados no aparecerán en esta documentación.

En los recibos encontramos informaciones muy interesantes como qué persona, el Bibliotecario o el Conserje, realiza el encargo al librero-encuadernador, fecha de la solicitud, el detalle de los libros que se mandan a encuadernar u otros encargos como carteras, pliegos de papel, entre otros, con la cantidad que se debe abonar por ejemplar o trabajo realizado, y el recibí con la fecha del pago y con las firmas dando el visto bueno de la Junta Particular y/o el Conserje junto a la firma del encuadernador constatando que ha recibido la cantidad acordada.

Una vez extraída la información sobre los gastos de cada encuadernador, se intentan localizar, mediante la escasa información que suministran los recibos, las obras en el depósito de la Biblioteca, labor bastante difícil ya que muchas han desaparecido con el tiempo, aunque otras sí permanecen en la Biblioteca. Localizada la obra, se digitaliza la encuadernación y se realiza un análisis de los aspectos más relevantes como materiales (pieles, papeles decorados...), técnicas de construcción (tipos de costuras...) y elementos decorativos, todo ello muy importante para el establecimiento de un corpus de hierros (florones, paletas y ruedas), y posterior comparación con otras encuadernaciones de la Academia o de otras instituciones donde pudiera haber trabajo el encuadernador.

En los estudios que estamos llevando a cabo sobre estos encuadernadores, hemos encontrado otros que trabajaron para la Real Academia.

\section{Estudio de los recibos y anotaciones sobre encargos de encua- dernaciones}

El encuadernador Pedro Martínez, artesano del último cuarto del siglo XVIII y de la primera década del XIX († 1808), con taller en Madrid, trabajó para la Real Academia 
2. Castañeda y Alcover, 1958: 1.

3. Gaceta de Madrid, $\mathrm{n}^{\circ}-11213$, 28/3/1775, p. 136 ; n-21, 23/5/1775, p. $208 ; n^{\circ} 38,19 / 9 / 1775$, p. 334 ; nํ $37,11 / 9 / 1778$, p. $384 ;$ n $\div 59$, 27/11/1778, p. 580; no $26,30 / 3 / 1779$, p. 224; no 44, 1/6/1779, p. 380 ; $\mathrm{n}^{\circ} 19,5 / 3 / 1784$, p. 211-212; no 112, 4/12/18o1, p. 1223-1224

4. Bibliotecario, BibliotecarioConservador, Vicebibliotecario y Adjunto entre 1793 y 1826.

5. Primer conserje de la Real Academia de Bellas Artes de San Fernando.

6. Papel de marquilla, papel de tina de tamaño medio entre el de marca y el de marca mayor. Tamaño del pliego del papel (43,5 x $63 \mathrm{~cm}$. Buonocore, 1976: 297).

7. Diseño de papel marmoleado realizado en España a mediados del siglo XVIII que consiste simplemente en dejar la pintura tal como cae en el líquido, produciendo un movimiento de la pintura hacia delante y hacia atrás hasta cubrir todo el baño, que da lugar a una serie de líneas que confieren un cierto movimiento al diseño. (Vélez Celemín, 2012: 301).

8. Encuadernación a la holandesa: Dícese de la encuadernación económica en que el cartón de la cubierta va forrado de papel, y de piel o tela el lomo y una pequeña parte de las tapas próxima al mismo. Si la tela o piel cubre hasta la tercera parte o mitad de las tapas, el libro está encuadernado en media holandesa, y si las puntas se cubren a su vez con tela o piel, el libro está encuadernado en holandesa puntas o media holandesa, respectivamente. (Buonocore, 1976: 191.)

Tipo de encuadernación caracterizada por utilizar piel para cubrir el lomo, y papel, tela u otro material para los planos, pudiendo construirse el libro metiéndolo en tapas o encartonándolo. Tiene variantes tales como la media holandesa, que es la encuadernación a la holandesa en la que la tela o piel cubre hasta la mitad o la tercera parte de la tapa; holandesa puntas cuando se aplica también piel en las puntas. Junto a estos tipos básicos hay variaciones si el libro

lleva nervios resaltados o lomo liso; también se considera holandesa denominaciones a veces con bandas o a la francesa la que aplica piel al lomo y a la parte delantera de las tapas. En cuanto al acabado, es tan variado como la calidad de los materiales que se le apliquen (piel, papel, tela más o menos ricas...). (Enciclopedia, 1998: 152.) de Bellas Artes de San Fernando entre los años 1794 y 1808 año en el que muere, según consta en los libros de cuentas del Archivo. No aparece entre los encuadernadores de renombre de finales del siglo XVIII y primeros del XIX por lo que pensamos que fuera uno de los encuadernadores al que se le encargaban trabajos para encuadernaciones sencillas, modestas, sin muchos alardes decorativos. Es posible que este encuadernador no trabajara para las Reales Academias de la Historia y de la Lengua, ya que Vicente Castañeda en su obra ${ }^{2}$ no hace mención a este encuadernador, seguramente porque estas dos instituciones ya tenían al taller de Sancha para la realización de gran parte de sus encuadernaciones.

Sí hemos encontrado alguna noticia en la Gaceta de Madrid desde el año 1775 hasta 1801, aunque siempre las referencias se refieren a Pedro Martínez como Librero en la Calle Carretas frente a Correos 3 .

El primero de los recibos que aparece en el Archivo de la Real Academia se refiere a un encargo de cuarenta y nueve encuadernaciones realizado por el Bibliotecario Académico D. Juan Pasqual Colomer ${ }^{4}$, con fecha del 29 de abril de 1794, y que recibió el pago de $1.446 \mathrm{r}^{\mathrm{s}} \mathrm{v}^{\mathrm{n}}$ (reales de vellón) de mano del conserje D. Juan Moreno y Sánchez $^{5}$ el 15 de mayo del mismo año.

Entre las obras encuadernadas se encuentran los tomos 27,28 y 29 del Dictionnaire pour lintelligence des auteurs classiques, grecs et latins, tant sacrés que profanes: contenant la géographie, l'histoire, la fable et les antiquités, de M. Sabbathier (Figura 1) (sig. B 2280, B 2282-2283-216 x 151 mm.-) a $6 \mathrm{r}^{\mathrm{s}} \mathrm{v}^{\mathrm{n}}$ cada uno, en $8^{\circ}$ marquilla ${ }^{6}$, encuadernados en piel lisa color marrón con siete estaciones y cinco nervios y una costura a diente de perro, con un encuadramiento de dos hilos gofrados en las tapas, un lomo que contiene en los entrenervios una composición ya preestablecida de un florón central con una bellota y motivos vegetales alrededor, todo ello con un encuadramiento de dos hilos a cada lado de los nervios y una paleta de dientes de ratón en las bandas verticales; los nervios y las cofias aparecen estampados con una paleta de hilos inclinados; la parte superior e inferior del lomo está ornamentada con una paleta de motivos zoomórficos y fitomórficos estilizados, junto a dos tejuelos en el segundo y tercer entrenervio de piel roja, el primero con la leyenda "DITIONNAIRE / DES AUTEURS / CLASIQUES" y el segundo "TOM. XXVII / MA, MA". Los cantos se muestran ornamentados con una rueda de dos hilos, todo ello dorado, además los cortes están teñidos de color rojo, las cabezadas son de hilos de color azul y blanco, la cinta de registro también es de color azul y finalmente las guardas son de papel marmoleado modelo "plegado español"7 de colores verde, marrón, negro y carmesí.

Otro ejemplar contiene la obra de la Geometria Prattica:Tratta Dagl'Elementi d'Euclide et altri Auttori (sig. C $97-350$ x 252 mm.-), en folio marquilla encuadernación tipo holandesa ${ }^{8}$ con una costura a punto seguido con guardas de papel blanco marmoleado modelo "plegado español" de colores verde, marrón, negro y carmesí, con un coste de $10 r^{s} v^{n}$.

La siguiente encuadernación contiene un tomo en $8^{\circ}$ las Observaciones sobre las bellas artes entre los antiguos hasta la conquista de Grecia por los romanos: Asunto propuesto en la Cátedra de Historia Literaria de los Reales Estudios de Madrid al concluirse el primer año del curso Académico (Figura 2) (sig. A $1830-166$ x 108 mm.-) con cinco estaciones, tres nervios y una costura a punto salteado; en cuanto a la ornamentación la piel está jaspeada con un moteado color marrón y un encuadramiento de un hilo dorado en las tapas, y una simulación de los nervios con una paleta de cuatro hilos dorados, los dos exteriores con pequeñas líneas alternas y un tejuelo de piel roja con la leyenda "BOSARTE / OBSERVACI / SOBRE LAS / ARTES"; la cabezada es de cordel de fibra vegetal retorcida recubierta de papel marmoleado, las guardas son también de papel 

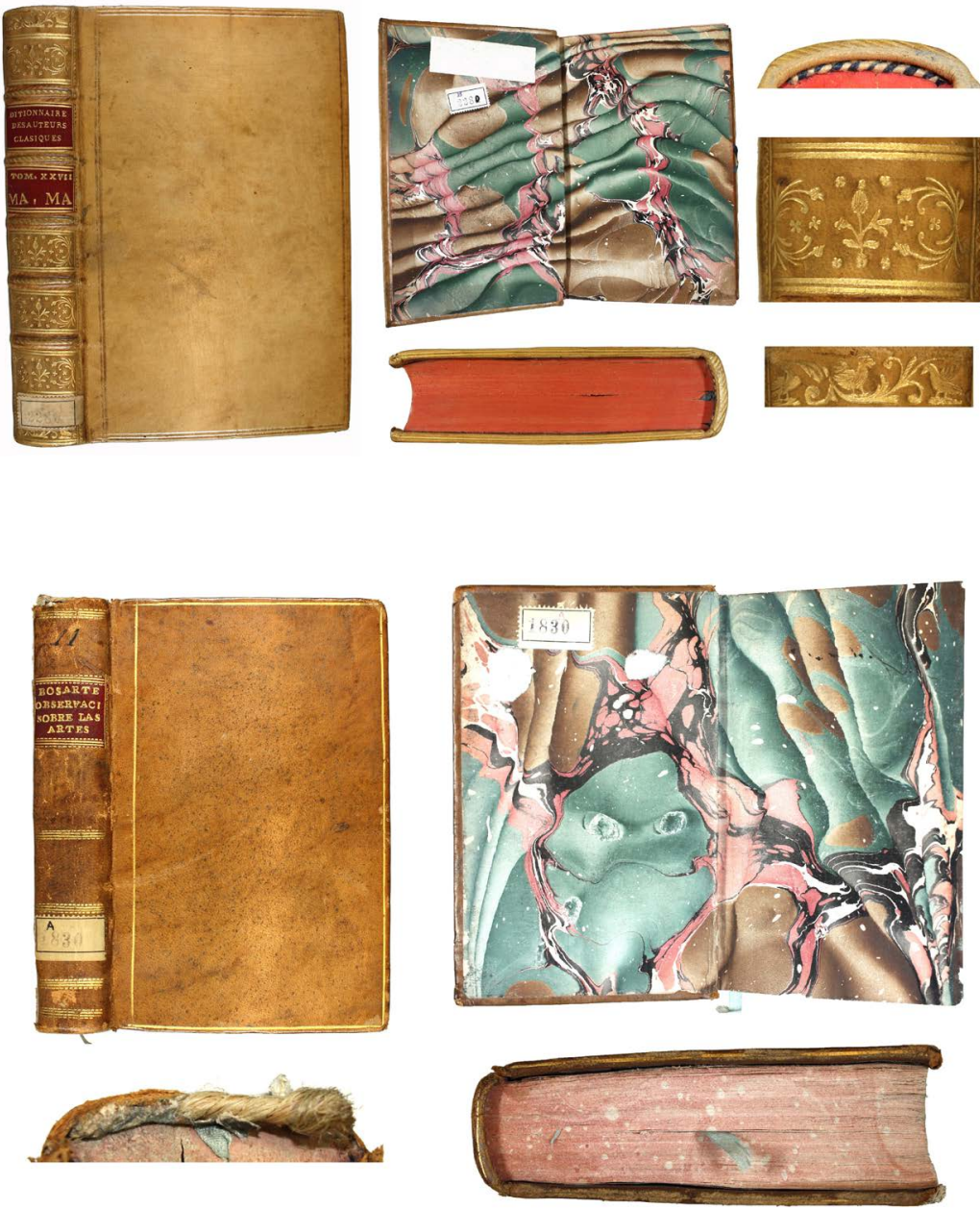

marmoleado modelo "plegado español" de colores verde, marrón, negro y carmesí, los cantos y cofias están decoradas con un hilo dorado, la cinta de registro es de tela color azul y los cortes están ornamentados con el teñido de color rojo con moteado de color blanco, con un coste de $3 r^{s} v^{n}$.?

Los dos siguientes recibos corresponden al año 1795, el primero de ellos, encargo del Bibliotecario D. Juan Pasqual Colomer, con fecha del 26 de agosto y con un coste total de $753 \mathrm{r}^{\mathrm{s}} \mathrm{v}^{\mathrm{n}}$. Es este encargo encontramos ciento diez encuadernaciones, entre ellas treinta y ocho de la Colección de vaciados de estatuas antiguas que posée la Real Academia de las Tres Nobles Artes de Madrid, de las que hemos localizados tres ejemplares (sig. C 6267, C 8311 y B $112-316$ x 226 mm.-) con un coste cada volumen de $8 \mathrm{r}^{\mathrm{s}} \mathrm{v}^{\mathrm{n}}$, con seis nervios y encuadernados en holandesa con puntas de piel y papel marmoleado modelo "plegado español" de colores verde, marrón, negro y carmesí, con nervios simulados mediante una paleta de cuatro hilos dorados, los dos exteriores con pequeñas líneas alternas, y los cortes están ornamentados con el jaspeado modelo "gotas" ${ }^{10}$ con los colores verde, carmesí, amarillo y negro.

El siguiente encargo es el Compendio de la geometría práctica: con un breve tratado para medirterrenos, diuidirlos y levantar planes arreglados a ellos (sig. B $2970-186$ x $121 \mathrm{~mm}$.), con un coste de $3 \mathrm{r}^{\mathrm{s}} \mathrm{v}^{\mathrm{n}}$, que contiene una costura a punto seguido junto a cinco estaciones y tres nervios, recubierta de pasta española, lomo liso ornamentado con
Figura 1. Sig, B 2280 - Tapa y guarda anterior, corte y cabezada superior, entrenervio y paleta

Figura 2. Sig. A 1830 - Tapa y guarda anterior, cabezada superior y corte inferior

9. Libro Tesorero. Libro de cuentas, Archivo de la Real Academia de Bellas Artes de San Fernando (RABASF), signatura 236/3, p. 31-32.

10. Diseño de papel marmoleado, también denominado Mármol, de primeros del siglo XVII, que consiste en dejar las gotas tal y como caen en la cubeta. (Vélez Celemín, 2012: 292). 
11. Es el libro sin tapa; tiene solamente una cubierta de papel o cartulina. Está cosido con puntos salteados y ligeramente encolado en el lomo. (Buonocore, 1976: 191.) Encuadernación en rústica, libro en rústica. Tipo de encuadernación que cubre el cuerpo del libro con una cartulina pegada por el lomo del mismo. La encuadernación en rústica es el modelo más sencillo de encuadernación y consiste en sujetar los pliegos con una costura no muy consistente cubriéndolos posteriormente con unas tapas o cubiertas realizadas con cartulina sin ningún otro material de refuerzo añadido. Desde el punto

de vista económico es la más barata de realizar y por tanto se utiliza en gran medida en el sector editorial y más escasamente en la encuadernación que podríamos llamar de bibliotecas o de particulares. (Enciclopedia, 1998: 257).

12. Libro Tesorero. Libro de cuentas, Archivo de la Real Academia de Bellas Artes de San Fernando (RABASF), signatura 237/3, recibo $n^{\circ} 68$, p. 119 una pequeña composición ya preestablecida de una florecilla de diez pétalos en los entrenervios, una paleta de dos hilos simulando los nervios, una paleta de florecillas de seis pétalos y motivos vegetales, tres en la parte inferior y una en la superior de lomo, junto a un tejuelo de piel roja con la leyenda "COMPE / DE / GEOME", todo ello dorado; las cabezadas son de cordel de fibra vegetal recubiertas de papel, los cortes están teñidos de color azul y las cinta de registro también son de tela color azul.

La siguiente encuadernación corresponde a un volumen con la obra Fiestas del Real Colegio Mayor de S. Clemente de los Españoles de Bolonia en la exâltacion al trono de los señores Reyes Catolicos D. Carlos IVy doña Marisa Luisa de Borbon (sig. C 314-396 x 269 mm.-), en folio con una encuadernación en rústica ${ }^{11}$ con un papel marmoleado modelo "gotas" de colores negro y diversas tonalidades de azul, con seis estaciones, cuatro nervios y con una costura a punto seguido siendo el coste de la encuadernación de $12 r^{\mathrm{s}} \mathrm{v}^{\mathrm{n}}$. La siguiente encuadernación corresponde a la Le rime del Petrarca (sig. A 950 $-179 \times 121 \mathrm{~mm} .-)$, holandesa en $8^{\circ}$, con tres nervios, cinco estaciones y una costura a punto salteado, con un papel marmoleado en las cubiertas modelo "plegado español" de colores verde, marrón, negro y carmesí, guardas de papel blanco, simulados con una paleta de cuatro hilos dorados, los dos exteriores con pequeñas líneas alternas, el encuadramiento de la leyenda del tejuelo está formado por la misma paleta de cuatro hilos horizontal y una paleta de dientes de ratón dispuesta en vertical con la leyenda en su interior "RIME / DI / PETRARCA", todo ello dorado, y los cortes están ornamentados con el marmoleado de color azul y negro.

Siguiendo el orden del recibo las tres encuadernaciones contienen la obra Decadas de Tito Livio: principe de la historia romana (sig. B 174-176-226 x 151 mm.-), con una estructura tipo holandesa con un papel marmoleado en las cubiertas modelo "plegado español" de colores verde, marrón, negro y carmesí, guardas de papel blanco, con cuatro nervios, seis estaciones y una costura a punto salteado, con los nervios simulados con una paleta de cuatro hilos, los dos exteriores con pequeñas líneas alternas, junto al encuadramiento de las leyendas están formados por la misma paleta de cuatro hilos horizontal y una paleta de dientes de ratón dispuesta en vertical con la leyenda en su interior "DECADAS / DE TITO / LIVIO / [No TOMO]", todo ello dorado, finalmente los cortes están marmoleados modelo "gotas" de color azul y negro, con un coste de $4 \mathrm{r}^{\mathrm{s}} \mathrm{v}^{\mathrm{n}}$ cada una.

Otra de las encuadernaciones del encargo corresponde a la obra Aminta:favola boscareccia (sig. B $1036-196 \times 123$ mm.-), tipo holandesa en $8^{\circ}$, con tres nervios, cinco estaciones y con una costura a punto salteado, con una decoración en el lomo y del papel marmoleado de las cubierta similar al anterior ejemplo, con la leyenda dorada "TASSO / AMINTA", con un coste de $4 \mathrm{r}^{\mathrm{s}} \mathrm{V}^{\mathrm{n}}$. Similares ornamentaciones a las encuadernaciones anteriores son los dos volúmenes siguientes, uno con la Poesie burlesche di Messer Francesco Berni: raccolte per la prima volta in un sol volume, e arricchite della vita dell'autore e di varie note (sig. A $984-196 \times 131 \mathrm{~mm}$.-) y otro con la obra Scelta di canzoni de' piu' eccellenti poeti antichi, e moderni (sig. A $983-196$ x 131 mm.-), ambos con tres nervios, cinco estaciones y una costura a punto salteado. El encargo fue abonado el 3 de septiembre del mismo año ${ }^{12}$.

El segundo recibo del 16 de diciembre de 1795 corresponde al encargo del Bibliotecario D. Juan Pascual Colomer de la encuadernación de veintiocho tomos con un total de $419 \mathrm{r}^{\mathrm{s}} \mathrm{v}^{\mathrm{n}} \mathrm{y}$ abonados el 22 de diciembre del mismo año. Los cuatro primeros tomos de tres obras contienen una ornamentación similar, tipo holandesa con un papel marmoleado en las cubiertas modelo "plegado español" de colores verde, marrón, negro y carmesí, guardas de papel blanco, con los nervios simulados con una paleta de cuatro hilos, los dos exteriores con pequeñas líneas alternas, el encuadramiento de las leyendas están formados por la misma paleta de cuatro hilos horizontal y una paleta 

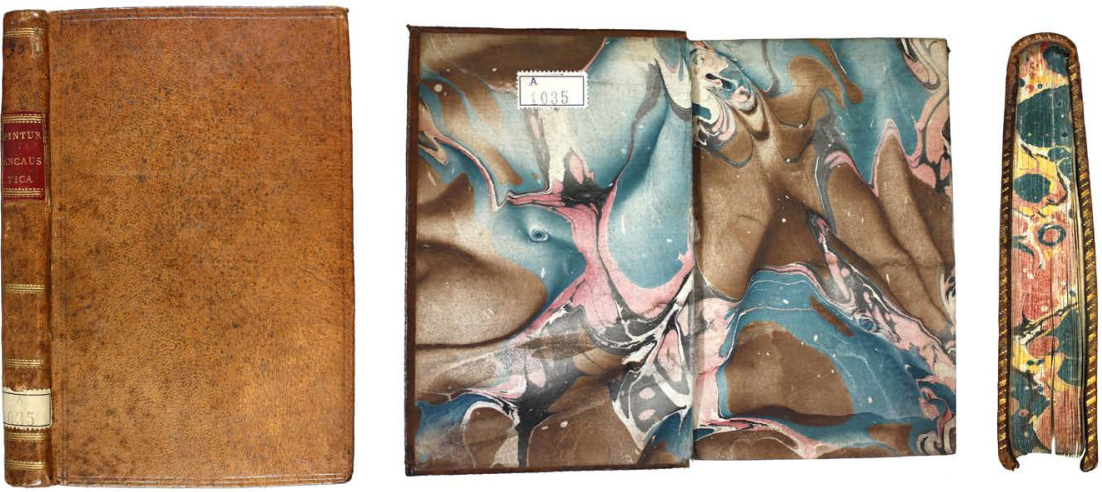

de dientes de ratón dispuesta en vertical con las leyendas en su interior: "SEPOLCR / ANTICHI" de la obra Gli antichi sepolcri overo Mausolei Romani et Etruschi, Trouati in Roma e in altri luoghi celebri, nelli quali si contengono molte erudite Memorie (sig. B 1220 $-350 \times 246 \mathrm{~mm} .-$ ) tamaño folio con un coste de $8 \mathrm{r}^{\mathrm{s}} \mathrm{v}^{\mathrm{n}}$; la leyenda dorada del segundo tomo contiene "VIDAS / DE LOS VAR / ILUSTRE / DE PLU / I o II" de la obra Vidas de los varones ilustres griegos y romanos (sig. B 449-450-226 $149 \mathrm{~mm} .-$ ) tamaño $4^{\circ}$ con tres nervios, cinco estaciones y una costura a punto salteado y un coste de $3 \mathrm{r}^{\mathrm{s}} \mathrm{v}^{\mathrm{n}}$ cada uno y la cuarta encuadernación con la obra Oracion Sobre la utilidad general de la instruccion del dibujo que en el dia diez y nueve de Noviembre de este año de 1778, destinado para la Abertura de la Escuela de Dibujo, mandada establecer por Reales Ordenes, en esta Ciudad de Segovia (sig. C $745-215 \times 151$ mm.-) tamaño $4^{\circ}$ con un coste de $3 \mathrm{r}^{\mathrm{s}} \mathrm{v}^{\mathrm{n}}$.

Otra encuadernación de este recibo contiene dos tomos de la obra Comentarios de pintura encáustica del pincel (Figura 3) (sig. A 1035 -186 x 119 mm.-) tamaño $8^{\circ}$ marquilla, con tres nervios, cinco estaciones y una costura a punto salteado, recubierta de pasta moteada de color marrón, con un encuadramiento gofrado de dos hilos, las guardas están marmoleadas modelo "plegado español" con tintas de colores marrón, azul, carmesí y negro, el lomo está ornamentado con los nervios simulados con una paleta de cuatro hilos, los dos exteriores con pequeñas líneas alternas, y un tejuelo de color rojo con encuadramiento formado por la misma paleta de cuatro hilos horizontal y una paleta de dientes de ratón dispuesta en vertical, con la leyenda en su interior "PINTUR / ENCAUS / TICA", los cantos y las cofias están ornamentadas con una rueda y paleta de dos hilos, uno más ancho y el otro con pequeñas líneas alternas, ambos inclinados, todo ello dorado, y los cortes están marmoleados modelo "gotas" de color azul carmesí, amarillo y negro, con un coste de $8 \mathrm{r}^{5} \mathrm{v}^{\mathrm{n}}$ los dos tomos ${ }^{13}$.

En el año 1796 el Bibliotecario D. Juan Pasqual Colomer encargó a este artesano la encuadernación de diez volúmenes para la biblioteca además de trescientos libros con la relación de los Premios, con una encuadernación en rústica y cosidos con telar, tal y como dice el recibo, todo ello con un coste de $406 \mathrm{r}^{\mathrm{s}} \mathrm{v}^{\mathrm{n}}$, 300 de los cuales fueron destinados para el pago de los trescientos libros de la Relación de Premios. Entre los diez tomos encontramos dos encuadernaciones que contienen la obra Decadas de Tito Livio: principe de la historia romana (sig. B 177-178-225 x 156 mm.-), con una estructura tipo holandesa con un papel marmoleado en las cubiertas modelo "plegado español" de colores verde, marrón, negro y carmesí, guardas de papel blanco, con cuatro nervios, seis estaciones y una costura a punto salteado, con los nervios simulados con una paleta de cuatro hilos, los dos exteriores con pequeñas líneas alternas; el encuadramiento de las leyendas está formado por la misma paleta de cuatro hilos horizontal y una paleta de dientes de ratón dispuesta en vertical con la leyenda en su interior "DECADAS / DE TITO / LIVIO / [N TOMO]", todo ello dorado, los cortes están
Figura 3. Sig. A 1035 - Tapa y guarda anterior $\mathrm{y}$ corte superior

13. Libro Tesorero. Libro de cuentas, Archivo de la Rea Academia de Bellas Artes de San Fernando (RABASF), signatura 237/3, recibo $n=69$, p. 121-122 
14. Libro Tesorero. Libro de cuentas, Archivo de la Real Academia de Bellas Artes de San Fernando (RABASF), signatura 238/3, recibo no 88 , p. 148.

15. Libro Tesorero. Libro de cuentas, Archivo de la Real Academia de Bellas Artes de San Fernando (RABASF), signatura 240/3, recibo no 62, p. 101.

16. Libro Tesorero. Libro de cuentas, Archivo de la Real Academia de Bellas Artes de San Fernando (RABASF), signatura 241/3, recibo no 60 , p. 104.

17. Libro Tesorero. Libro de cuentas, Archivo de la Real Academia de Bellas Artes de San Fernando (RABASF), signatura 243/3, recibo $n^{\circ} 87$, p. 127 . marmoleados modelo "gotas" de color azul y negro, con un coste de $4 \mathrm{r}^{\mathrm{s}} \mathrm{v}^{\mathrm{n}}$ cada una. Las dos últimas encuadernaciones que ponemos como ejemplo de este recibo contiene la obra Historia natural de Cayo Plinio Segundo (sig. C 340-341-286 x 190 mm.-) con una estructura constructiva similar a los dos anteriores tomos de cinco nervios, siete estaciones y una costura a punto salteado, así como una holandesa de puntas con la misma ornamentación dorada en el lomo y con os cortes marmoleados. En la nota de entrega realizada por el encuadernador consta la fecha del 4 de noviembre y parece ser que el pago se realizó el 7 de noviembre, según consta también en la nota ${ }^{14}$.

El siguiente de los recibos referidos a este siglo XVIII es del año $1798^{15}$, del 17 de julio, con un coste total de $360 \mathrm{r}^{\mathrm{s}} \mathrm{v}^{\mathrm{n}}$ por la encuadernación cuarenta tomos, entre ellas dos encuadernaciones que contienen la obra Biblioteca española de Joseph Rodríguez de Castro, impresa en Madrid en la Imprenta Real de la Gazeta entre 1781 y 1786 (Figura 4) (sig. A 450-451-346 x 240 mm.-), tamaño folio, con cinco nervios, siete estaciones y una costura a punto salteado, con una ornamentación tipo holandesa de puntas, con seis falsos nervios decorados con una paleta de hilos inclinados, los entrenervios con una paleta de cuatro hilos, los dos exteriores con pequeñas líneas alternas y el segundo y tercer entrenervio con un encuadramiento formado con esta misma paleta a cada lado de los nervios y otra paleta dispuesta en vertical de dientes de ratón, con las leyendas "CASTRO / BIBLIOTE / ESPAÑOL" y el segundo con una paleta de motivos vegetales trenzados y el "[N $\left.\mathrm{N}^{\circ} \mathrm{TOMO}\right]$ ", todo ello dorado, además los cortes están marmoleados con tintas de colores carmesí, amarillo, verde y negro, con un coste de $12 \mathrm{r}^{\mathrm{s}} \mathrm{v}^{\mathrm{n}}$ cada una. La ornamentación del lomo es similar a los volúmenes con sig. C 340-341.

Un segundo ejemplo de este encargo es el volumen que contiene la obra Essais sur la peinture de Diderot (Figura 5) (sig. A 788 -216 x 149 mm.-), una encuadernación tipo holandesa en tamaño $8^{\text {a }}$, con seis estaciones de costura, cuatro nervios y una costura a punto seguido y cabezadas recubiertas de papel marmoleado, con un coste de 4 $\mathrm{r}^{\mathrm{s}} \mathrm{v}^{\mathrm{n}}$. El pago al encuadernador se realizó el 8 de agosto de 1798.

Otro ejemplo es la encuadernación tipo holandesa de los dos volúmenes de la obra Historia natural de Cayo Plinio Segundo, traducida por Gerónimo de Huerta, impresa en Madrid por Luis Sánchez entre 1624 y 1629 (sig. C 8595-8596 -296 x 215 mm.-)

En el año $1799^{16}$ (Figura 6) encontramos un recibo donde se indica el encargo del conserje D. Francisco Durán para la encuadernación de setenta y tres ejemplares de la Oración pronunciada en la Junta Pública que celebró la Real Academia de San Fernando el día 13 de julio de 1799, para la distribución de premios generales por Ramón Cabrera, impresa por Ibarra (sig. F 1808 -250 x 178 mm.-) junto a la encuadernación de un libro en blanco para la matrícula de los discípulos, con un montante de $85,12 \mathrm{r}^{\mathrm{s}} \mathrm{v}^{\mathrm{n}}$, satisfechos el 10 de noviembre del mismo año.

Con fecha del 1 de junio de 1800 tenemos otro recibo con varios encargos de encuadernaciones como veinte ejemplares del tomo $1^{\circ}$ del Diccionario histórico de los más ilustres profesores de la bellas artes en España, compuesto por Juan Agustín Cean Bermúdez, impreso por la viuda de Ibarra en 1800 (Figura 7) (sig. A 198-203-195 x 134 mm.- $)^{17}$ tamaño $8^{\circ}$, con una encuadernación en pasta jaspeada color marrón, con cuatro nervios y seis estaciones de costura, lomo liso sin nervios, tejuelos de piel color rojo, junto a una decoración en las tapas de una orla exterior de óvalos de pequeñas perlas unidas por estrellas de seis puntas y en el lomo un florón en cada entrenervios de tres círculos de puntos y una paleta de dos líneas interiores y otras dos exteriores con pequeñas líneas alternas, y otra paleta dentada en las bandas verticales de los tejuelos, elementos decorativos típicos de ese encuadernador, junto a una guardas marmoleadas de colores verde, marrón, rosa y negro y cortes igualmente 

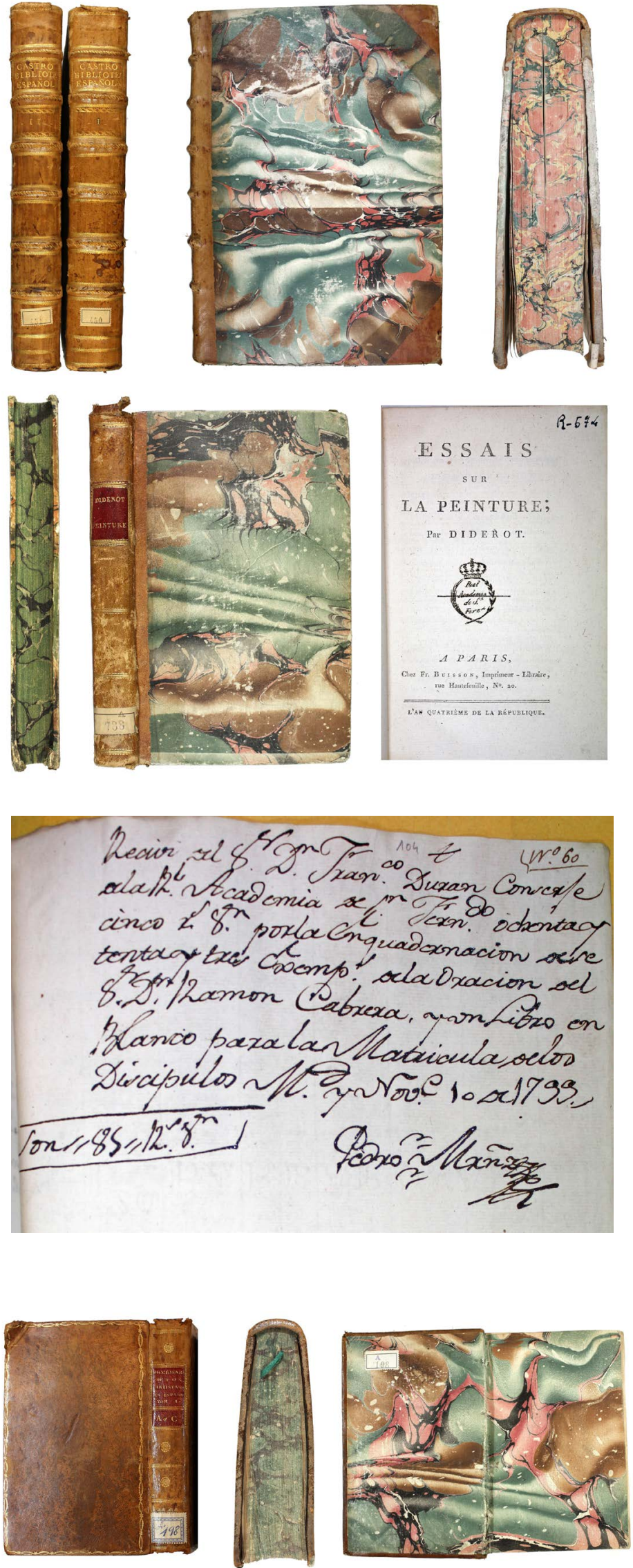

Figura 4. Sig. A 450-451 - Lomo, tapa anterior y corte inferior

Figura 5. Sig. A 788 - Corte delantero, tapa anterior y portada

Figura 6. Sig. 241/3, recibo no 60 , p. $104-1799$

Figura 7. Sig. A 198 - Tapa posterior y lomo, corte inferior y guarda anterior 
18. Libro Tesorero. Libro de cuentas, Archivo de la Real Academia de Bellas Artes de San Fernando (RABASF), signatura $243 / 3$, recibo no 64 , p. 102.

19. Libro Tesorero. Libro de cuentas, Archivo de la Real Academia de Bellas Artes de San Fernando (RABASF), signatura 243/3, recibo $n^{\circ} 69$, p. 107.

20. Libro Tesorero. Libro de cuentas, Archivo de la Real Academia de Bellas Artes de San Fernando (RABASF), signatura $244 / 3$, recibo no 118 , p. 166. marmoleados de colores verde y negro, a $6 \mathrm{r}^{\mathrm{s}} \mathrm{v}^{\mathrm{n}}$ cada uno; también en el recibo aparece el encargo de diez tomos en tafilete encarnado, con cortes, cantos y contracantos dorados a $25 \mathrm{r}^{\mathrm{s}} \mathrm{v}^{\mathrm{n}}$ cada uno, haciendo un montante de $370 \mathrm{r}^{\mathrm{s}} \mathrm{v}^{\mathrm{n}}$.

En la parte inferior del recibo se incluye también otra nota donde se encarga a Pedro Martínez la encuadernación del tomo $2^{\circ}$ en los mismos términos que el $1^{\mathrm{er}}$ tomo, con el mismo montante de $370 \mathrm{r}^{\mathrm{s}} \mathrm{V}^{\mathrm{n}}$, abonados el 17 de julio de 1800 .

En el reverso del recibo $n^{\circ} 87$, p. 127 , se encargan nuevas encuadernaciones al artesano: el primero de los encargos tiene fecha del 2 de septiembre de 1800 para la encuadernación del tomo $3^{\circ}$ por un montante de $370 \mathrm{r}^{\mathrm{s}} \mathrm{v}^{\mathrm{n}}$; el segundo encargo con fecha del 25 de octubre para la encuadernación de tomo $4^{\circ}$ por $370 \mathrm{r}^{\mathrm{s}} \mathrm{v}^{\mathrm{n}}$; el tercer encargo con fecha del 22 de diciembre para la encuadernación del tomo $5^{\circ}$ con la misma cantidad y el último apunte se refiere a la encuadernación del tomo $6^{\circ}$, con fecha de 7 de marzo de 1801, por la misma cantidad de $370 \mathrm{r}^{\mathrm{s}} \mathrm{v}^{\mathrm{n}}$.

En el mismo libro de cuentas aparece un recibo del 12 de febrero de $1802^{18} \mathrm{con}$ el encargo del Bibliotecario de la Academia D. Juan Gómez al encuadernador Pedro Martínez para la realización de trece encuadernaciones, entre ellas un tomo en folio manuscrito de la Junta preparatoria encuadernado en tafilete encarnado con cortes dorados junto a cantos, contracantos y orlas doradas a $75 \mathrm{r}^{\mathrm{s}} \mathrm{v}^{\mathrm{n}}$; otros tres tomos iguales en rústica a $6 \mathrm{r}^{\mathrm{s}} \mathrm{v}^{\mathrm{n}}$ cada uno; dos tomos de Gacetas de dos años enteros con una encuadernación holandesa a $6 \mathrm{r}^{\mathrm{s}} \mathrm{v}^{\mathrm{n}}$ cada uno; otros dos tomos en $8^{\circ}$ de la obra Constantinople ancienne et moderne et description des côtes et isles de l'Archipel et de la Troade, del autor Jacques Dallaway (sig. B 428-429-217 X 153 mm.-), con una encuadernación holandesa con hierros dorados en el lomo y cortes veteados, a $5 \mathrm{r}^{\mathrm{s}} \mathrm{v}^{\mathrm{n}}$ cada uno.

En ese mismo recibo también hallamos dos tomos del Dictionnaire portatifet de prononciation espagnol-français et français-espagnol a l'usage des deux nations : composé et rédigé fidellement d'après la dernière édition du Dictionnaire de l'Académie Royale Espagnole et les meilleurs Dictionnaires Français, de J.L. Barthelemi Cormon impreso en Paris en 1800 (B 2301-2302-216 X 149 mm.-), tamaño $8^{\circ}$, con cuatro nervios y seis estaciones de costura a punto salteado, lomo liso y curvo con tejuelos de piel roja, con una decoración en las tapas de un encuadramiento de dos hilos gofrados, el lomo está ornamentado por paletas de dos hilos flanqueados de otro hilo con pequeñas líneas alternas en el lomo y una paleta dentada en las bandas de los tejuelos, todo ello dorado, las guardas son de papel marmoleado modelo "plegado español" de colores marrón, verde, rosa y negro, los cortes están marmoleados con colores verde y negro, los cantos están ornamentados con un hilo dorado y las cofias con una paleta dorada de hilos inclinados alternándose gruesos y punteados y cinta de registro de color verde, con un coste de a $6 \mathrm{r}^{s} \mathrm{v}^{\mathrm{n}}$ cada uno de los tomos.

En otro recibo del mismo libro de cuentas, con fecha del 12 de febrero de $1802^{19}$, encontramos el pedido de catorce encuadernaciones de la nueva aritmética y geometría de la Real Academia, dos en pasta fina a $8 \mathrm{r}^{s} \mathrm{v}^{\mathrm{n}}$ cada uno, otros cuatro en pasta con cantos dorados a $6 \mathrm{r}^{\mathrm{s}} \mathrm{v}^{\mathrm{n}}$ cada uno y otros ocho en pasta regular a $5,5 \mathrm{r}^{\mathrm{s}} \mathrm{v}^{\mathrm{n}}$ cada uno, haciendo un montante total de $237 \mathrm{r}^{\mathrm{s}} \mathrm{v}^{\mathrm{n}}$.

El siguiente recibo lo encontramos el 7 de marzo de $1802^{20}$ (sig. 244/3) cuando se hace el encargo por parte del conserje D. Francisco Durán de la encuadernación de dieciocho tomos de la obra Diccionario de Arquitectura Civil de D. Benito Bails, impresa en Madrid por la viuda de Ibarra en 1802 (Figura 8) (sig. B $1763-225$ x 169 mm.-), tamaño $4^{\circ}$, con siete nervios, lomo liso y curvo, y con una ornamentación en las tapas de pasta española realizada con una rueda dorada de óvalos de perlas unidas con flores de seis pétalos; el lomo está decorado con paletas de dos hilos flanqueados por 

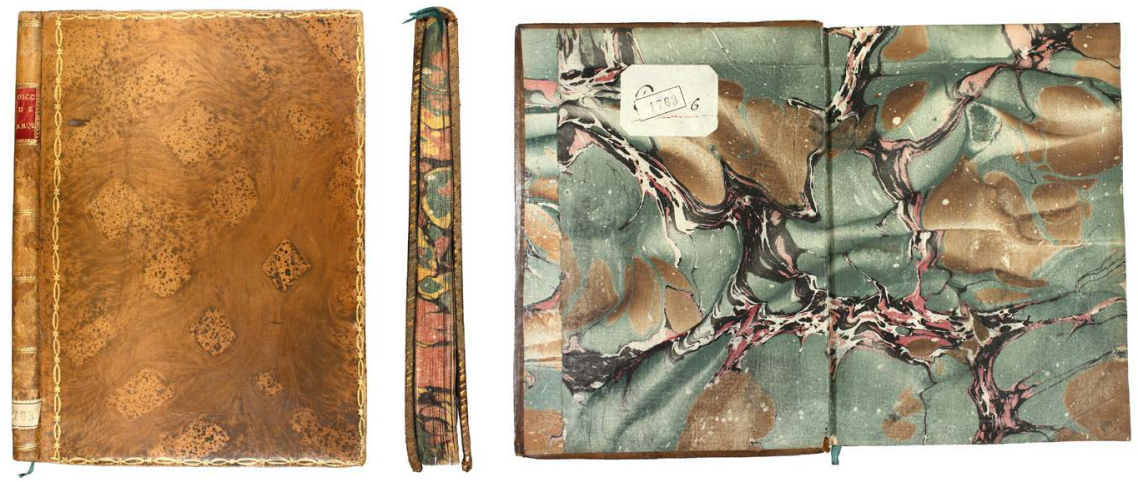

Figura 8. Sig. B 1763 - Tapa anterior y lomo, corte inferior y guarda anterior otros dos hilos con pequeñas líneas alternas, que imitan los nervios, junto a un tejuelo de piel roja, con una paleta dentada en las bandas verticales, todo ello dorado; los cortes están marmoleados con colores verde, amarillo, rojo y negro, los cantos y cofias están decorados con una rueda y paleta respectivamente de hilos inclinados, uno grueso y otro con pequeñas líneas alternas, las guardas son de papel marmoleado modelo "plegado español" de colores verde, rosa, negro y marrón y la cinta de registro es de tela color verde.

El coste de cada encuadernación, según consta en la nota manuscrita del encuadernador, es de $7 \mathrm{r}^{\mathrm{s}} \mathrm{v}^{\mathrm{n}}$ cada uno con los cantos dorados, y otros ocho en pasta fina a 10 $\mathrm{r}^{s} \mathrm{v}^{\mathrm{n}}$ cada uno, con un total de $156 \mathrm{r}^{\mathrm{s}} \mathrm{v}^{\mathrm{n}}$. En la parte inferior se muestra una nota donde se indica, por parte del conserje, que hay que descontar de la cuenta cierta cantidad ya que solo aparecen cantos dorados en seis tomos, lo que suma $42 \mathrm{r}^{\mathrm{s}} \mathrm{v}^{\mathrm{n}}$, junto a doce tomos más sin ornamentación en los cortes a $6 \mathrm{r}^{s} \mathrm{v}^{\mathrm{n}}$ cada uno, lo que hace que el total final sea de $144 \mathrm{r}^{\mathrm{s}} \mathrm{v}^{\mathrm{n}}$ en lugar de 156 como indicaba el encuadernador.

Otro encargo del mismo año, esta vez del 2 de diciembre, solicita al artesano lleve a cabo la encuadernación de la Distribución de los premios concedidos por el Rey Nuestro Señor á los discípulos de las tres Nobles Artes realizada por la Real Academia de San Fernando en la Junta Pública de 24 de julio de $1802^{21}$ con un total de setecientos sesenta y tres encuadernaciones, (sig. A $280-298$ x 206 mm.-) de ellos dos tomos en tafilete encarnado con sus cantos, contracantos y orlas doradas, a $30 \mathrm{r}^{\mathrm{s}} \mathrm{v}^{\mathrm{n}}$ cada uno; un libro de los Estatutos de la Real Academia para regalar a la Infanta Princesa de Nápoles, con una ornamentación similar a los dos tomos anteriores, a $30 \mathrm{r}^{\mathrm{s}} \mathrm{v}^{\mathrm{n}}$; otros doce ejemplares en pasta fina con cantos y orlas doradas a $10 \mathrm{r}^{\mathrm{s}} \mathrm{v}^{\mathrm{n}}$ cada uno; otros cien ejemplares en pasta con sus cantos dorados, a $8 \mathrm{r}^{\mathrm{s}} \mathrm{v}^{\mathrm{n}}$ cada uno; y otros seiscientos treinta ejemplares en rústica recubiertos de papel fino azulado a $1 \mathrm{r}^{\mathrm{s}} \mathrm{v}^{\mathrm{n}}$ cada uno, haciendo un total de $1646 \mathrm{r}^{\mathrm{s}} \mathrm{v}^{\mathrm{n}}$, dando el visto bueno para el pago la Junta Particular el 29 de diciembre de 1802 .

Habrá que esperar hasta 1804 para encontrarnos otro encargo de encuadernaciones realizado a este artesano, en concreto con fecha del 8 de mayo ${ }^{22}$, donde se indica que debe realizar treinta y cuatro encuadernaciones, comenzando por una cartilla de monumentos en pasta con orla dorada a $80 \mathrm{r}^{\mathrm{s}} \mathrm{v}^{\mathrm{n}}$; un libro de pavimentos a la holandesa con puntas de piel a $40 \mathrm{r}^{\mathrm{s}} \mathrm{v}^{\mathrm{n}}$; un cuaderno de relieves antiguos también a la holandesa con puntas a $40 \mathrm{r}^{\mathrm{s}} \mathrm{v}^{\mathrm{n}}$; también la Colección de los edificios y planes del célebre arquitecto Andrea Paladio, del autor Carlos Félix de Vargas Machuca (sig. C 1518-446 x 295 mm.-), tamaño folio y con una encuadernación tipo holandesa de puntas, sin cabezadas y guardas de papel blanco, a $60 \mathrm{r}^{\mathrm{s}} \mathrm{v}^{\mathrm{n}}$; la obra Statica degli edifici di Vincenzo Lamberti, impresa en Nápoles en 1781 (sig. B 1721 -256 x 148 mm.-), tamaño $4^{\circ}$, sin cabezada, con cuatro nervios y seis estaciones de costura a punto seguido, guardas
21. Libro Tesorero. Libro de cuentas, Archivo de la Real Academia de Bellas Artes de San Fernando (RABASF), signatura sig. 244/3, recibo no 91, p. 136.

22. Libro Tesorero. Libro de cuentas, Archivo de la Rea Academia de Bellas Artes de San Fernando (RABASF), signatura $246 / 3$, recibo $n^{\circ} 74$, p. 124-125. 
Figura 9. Sig. B $1560-$ Tapa anterior y lomo / Sig. B 1775 - Tapa anterior y lomo y corte inferior
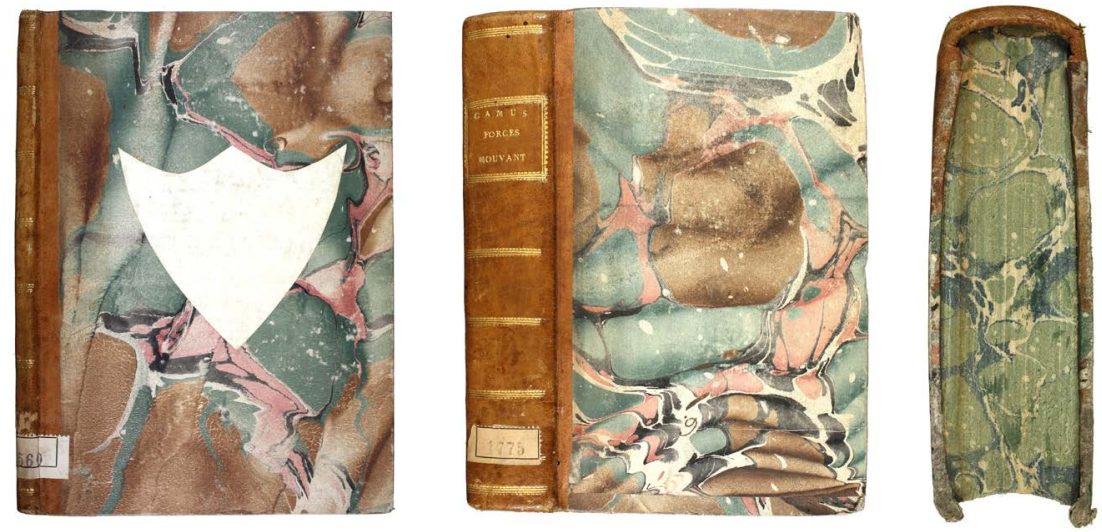

de papel blanco, con cortes marmoleados y una encuadernación tipo holandesa de puntas, a $8 \mathrm{r}^{\mathrm{s}} \mathrm{v}^{\mathrm{n}}$; otra encuadernación contiene la obra Degli archi e delle volte libri sei, de Leonardo Salimbeni, impresa en Verona en 1787 (sig. B $2014-306$ x $221 \mathrm{~mm} .-$ ), tamaño $4^{\circ}$, con cuatro nervios y seis estaciones de costura a punto salteado, guardas de papel blanco, sin cabezadas y con los cortes marmoleados, a $8 \mathrm{r}^{\mathrm{s}} \mathrm{v}^{\mathrm{n}}$; también la obra Le génie de l'architecture ou L'analogie de cet art avec nos sensations, de M. le Camus de Mézieres, impresa en Paris en 1780 (B 2363-195 X $139 \mathrm{~mm} .-)$, tamaño $8^{\circ}$, con cuatro nervios y seis estaciones de costura a punto seguido, guardas de papel blanco, encuadernación tipo holandesa con puntas y cortes marmoleados, a $5 \mathrm{r}^{\mathrm{s}} \mathrm{v}^{\mathrm{n}}$; otra obra más es Trattato teorico-pratico di prospettiva, de Eustachio Zanotti, impresa en Bologna en 1766 (sig. A $459-256$ x 166 mm.-), tamaño $4^{\circ}$, con guardas de papel blanco, sin cabezadas, con cuatro nervios y seis estaciones de costura a punto seguido, cortes marmoleados y una encuadernación holandesa de puntas, a $8 \mathrm{r}^{\mathrm{s}} \mathrm{v}^{\mathrm{n}}$.

La siguiente encuadernación contiene la obra Disertacion sobre el teatro y circo de Sagunto, ahora villa de Murviedro, por Enrique Palos y Navarro, impresa en Valencia en 1793 (Figura 9) (sig. B $1560-212 \times 129 \mathrm{~mm} .-$ ), tamaño $4^{\circ}$, tipo holandesa que contiene un hueco en la tapa anterior con forma de escudo, guardas de papel blanco, sin cabezadas, sin cortes pintados y con siete estaciones de costura, a 5 $\mathrm{r}^{\mathrm{s}} \mathrm{v}^{\mathrm{n}}$; la encuadernación siguiente contiene la obra Traité des forces mouvantes, de Monsieur De Camus, impresa en Paris en 1722 (Figura 9) (sig. B 1775-208 x 151 mm.-), tamaño $8^{\circ}$, holandesa sin puntas, guardas de papel blanco, sin tejuelo de piel, con cuatro nervios y seis estaciones de costura a punto salteado y cortes marmoleados con colores verde, blanco y negro, a $5 \mathrm{r}^{\mathrm{s}} \mathrm{v}^{\mathrm{n}}$, entre otras encuadernaciones, haciendo un total de $464 \mathrm{r}^{\mathrm{s}} \mathrm{v}^{\mathrm{n}}$, realizándose el pago el 17 de mayo del mismo año.

23. Libro Tesorero. Libro de cuentas, Archivo de la Real Academia de Bellas Artes de San Fernando (RABASF), signatura 246/3, recibo no 75 , p. 126.
Otro recibo de ese mismo año, del 22 de diciembre de $1804^{23}$, indica las ciento once encuadernaciones encargadas al artesano, como la encuadernación de un juego de cuatro Actas de la Academia en pasta con los cortes dorados, cantos, contracantos y orlas también dorado, todo por $100 \mathrm{r}^{\mathrm{s}} \mathrm{v}^{\mathrm{n}}$; otros cien ejemplares de la obra Antigüedades árabes de España, publicada por la Real Academia de Bellas Artes de San Fernando, impresa por la Imprenta Real en 1804, por la impresión y estampas, batidos, costura y recubrimiento de papel blanco, es decir una encuadernación en rústica, a $4 \mathrm{r}^{\mathrm{s}} \mathrm{v}^{\mathrm{n}}$ cada uno; un juego de seis tomos del Diccionario histórico de los más ilustres profesores de la bellas artes en España, compuesto por Juan Agustín Cean Bermúdez, impreso por la viuda de Ibarra en 1800 (similar al visto en 1800 sig. A 198-203-195 x 134 mm.-), encuadernado en pasta, a $7 \mathrm{r}^{\mathrm{s}} \mathrm{v}^{\mathrm{n}}$ cada uno, haciendo un total todo el encargo de 550 $\mathrm{r}^{\mathrm{s}} \mathrm{v}^{\mathrm{n}}$. 


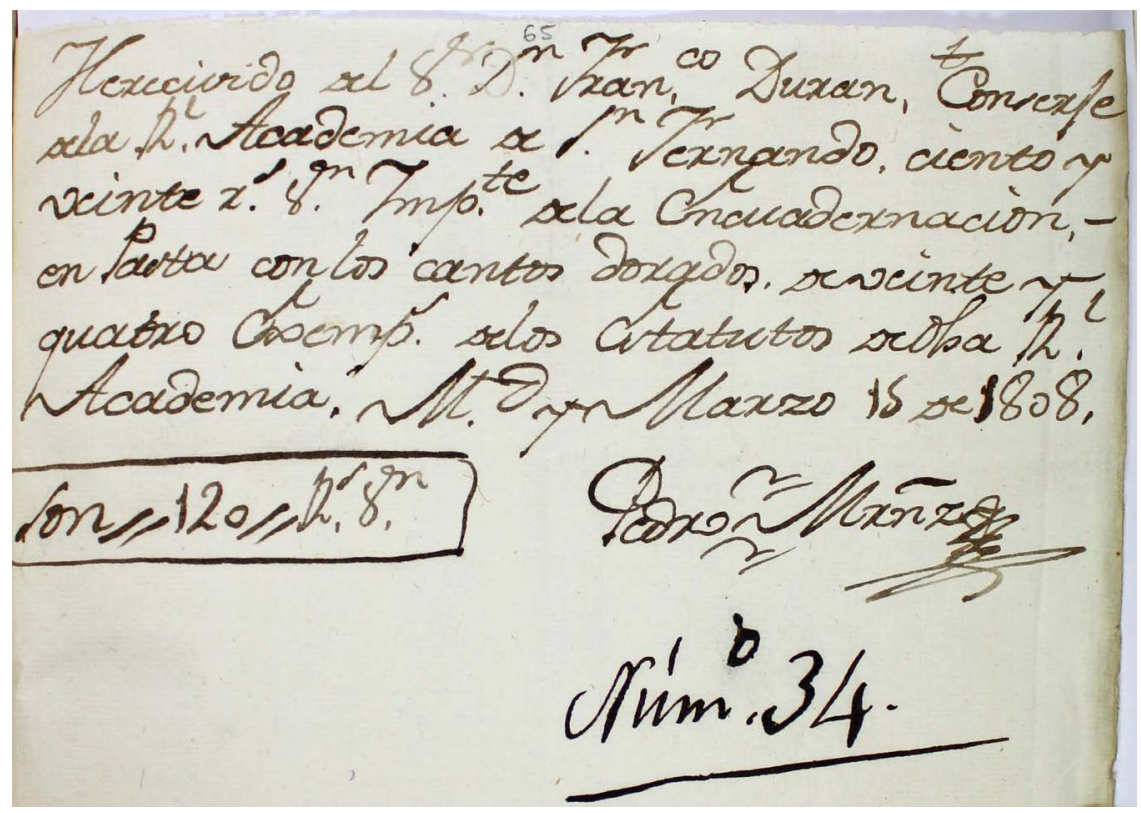

En este mismo Libro de cuentas ${ }^{24}$, en la p. 19, se encuentra una anotación manuscrita con fecha de 1805 donde se indica:

“He recibido del Librero $D^{n}$ Pedro Martínez, cien quadernos de las treinta estampas del segundo quaderno de las Antiguedades Arabes de Granada, con su explicación impresa, enquadernados con cubierta de papel blanco, pertenecientes ala R! Academia de $\mathrm{S}^{\mathrm{n}}$. Fernando. Madrid 20 de Febro de 1805.

\section{Fran ${ }^{c o}$ Duran"}

El siguiente encargo a este encuadernador tiene fecha del 6 de diciembre de $1806^{25}$, y en el se indica la encuadernación de ciento catorce ejemplares de Actas o Distribución de Premios de la Real Academia, comenzando con dos ejemplares en tafilete encarnado con cantos, contracantos y orlas doradas, a $40 \mathrm{r}^{s} \mathrm{v}^{\mathrm{n}}$ cada uno; otros doce más en tafilete como los anteriores a $12 \mathrm{r}^{\mathrm{s}} \mathrm{v}^{\mathrm{n}}$ cada uno; cien más en pasta común a $9 \mathrm{r}^{\mathrm{s}} \mathrm{v}^{\mathrm{n}}$ cada uno; y finalmente seiscientos ejemplares en rústica a $1 \mathrm{r}^{\mathrm{s}} \mathrm{v}^{\mathrm{n}}$ cada uno, haciendo un total la cuenta de $1724 \mathrm{r}^{\mathrm{s}} \mathrm{v}^{\mathrm{n}}$.

El último recibo que hemos localizado de este artesano corresponde al 15 de marzo de $1808^{26}$ (Figura 10), donde el conserje D. Francisco Durán encarga al Pedro Martínez la encuadernación en pasta con los cantos dorados de veinticuatro ejemplares de los Estatutos de la Academia por un total de $120 \mathrm{r}^{s} \mathrm{v}^{\mathrm{n}}$, es decir a $5 \mathrm{r}^{\mathrm{s}} \mathrm{v}^{\mathrm{n}}$ cada uno, tal y como se puede observar en la imagen siguiente con el recibo original manuscrito.

\section{Conclusiones}

Para finalizar esta exposición de recopilación, búsqueda y estudio de los trabajos realizados por el encuadernador Pedro Martínez, queremos indicar que se han localizado 17 recibos o notas entre abril de 1794 hasta marzo de 1808 , con un total de 2.282 encuadernaciones realizadas más una cartera de piel, que aparece en el primer encargo de 1794 .

Destaca también el encargo de agosto de 1795 con ciento diez encuadernaciones de diferentes tipos y obras. Sobresalen por su número la encuadernación de la
Figura 10. Sig. 250/3, recibo $n^{\circ} 34$, p. $65-1808$

24. Libro Tesorero. Libro de cuentas, Archivo de la Real Academia de Bellas Artes de San Fernando (RABASF), signatura sig. 246/3, p. 19.

25. Libro Tesorero. Libro de cuentas, Archivo de la Real Academia de Bellas Artes de San Fernando (RABASF), signatura sig. 248/3, recibo no 87, p. 122.

26. Libro Tesorero. Libro de cuentas, Archivo de la Real Academia de Bellas Artes de San Fernando (RABASF), signatura sig. $250 / 3$, recibo $\mathrm{n}^{\circ} 34$, p. 65 . 
Figura 11. Paletas doradas del lomo, florones y ruedas
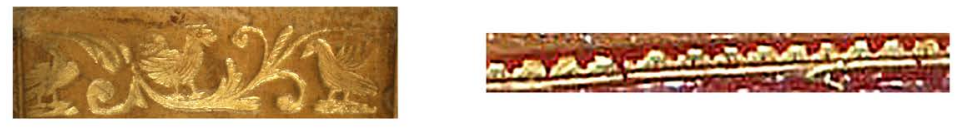

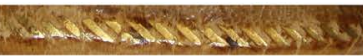
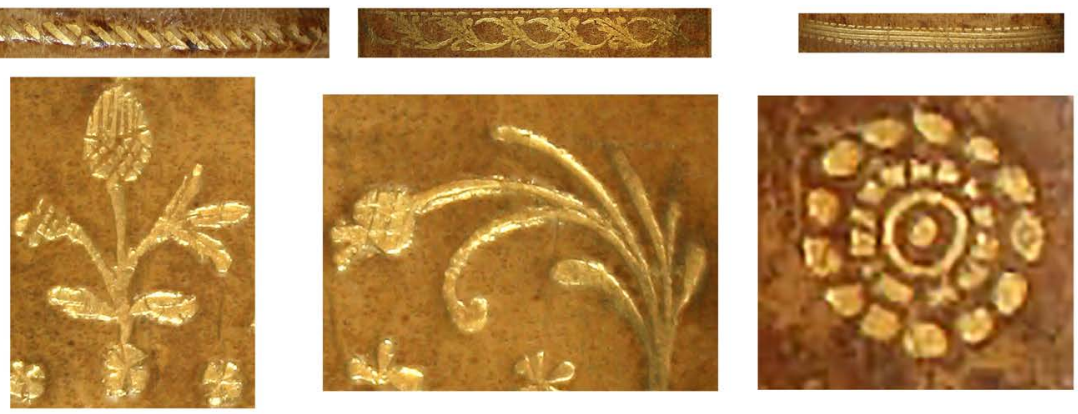

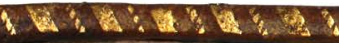

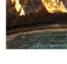

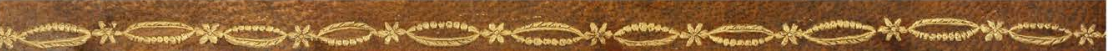

Distribución de Premios, de noviembre del año 1796, con trescientos ejemplares en "rústica"; los seiscientos ejemplares de la misma obra, en diciembre de 1802 , en "rústica" recubiertos de papel azulado, junto a otros cien ejemplares encuadernados en "pasta con cantos dorados"; otros seiscientos en "rústica", junto a cien más en "pasta", en diciembre de 1806. Además resalta el encargo de cien ejemplares de la obra Antigüedades árabes de España, también en rústica, en diciembre de 1804. Como se puede observar el tipo de encuadernación predominante es la "rústica", seguida de la "pasta jaspeada" o "española" y después los recubrimientos en "tafilete", destacando las guardas marmoleadas y las de papel blanco.

En cuanto a las técnicas de construcción, se emplean indistintamente la costura a punto seguido y la de punto salteado, aunque también hemos encontrados diversas modalidades a diente de perro, predominando los ejemplares en formato $4^{\circ}$ y $8^{\circ}$, con cuatro nervios y seis estaciones de costura.

En las encuadernaciones en "tafilete" y "pasta", (Figura 11) las tapas están decoradas con un encuadramiento de dos hilos gofrados o uno dorado y también en otros ejemplares aparece una rueda de óvalos con perlas unidos con estrellas de seis puntas; los lomos, lisos y redondeados, simulan los nervios con una paleta de dos hilos flanqueada por otros dos hilos con pequeñas líneas alternas, paleta utilizada también para realizar el encuadramiento de los tejuelos, junto a otra paleta vertical dentada; alguna encuadernación con falsos nervios se ha decorado con paletas de hilos inclinados, junto a otras de motivos vegetales entrelazados, apareciendo un florón de círculos punteados en los entrenervios; los cantos se muestran en ocasiones decorados con una rueda de un hilo o de hilos inclinados, unos más gruesos y otros con pequeñas líneas alternas, al igual que la paleta utilizada para la decoración de las cofias; los cortes aparece frecuentemente marmoleados.

Observando estos datos podemos indicar que este encuadernador realizó, sobre todo, encuadernaciones sencillas, modestas, en piel pero sin excesivos elementos dorados, muchas de ellas en "rústica" para documentos como Actas, Estatutos y Distribución de Premios.

También podemos comparar trabajos similares realizados por diferentes encuadernadores, observando que el precio que pagaba la Academia podía variar sustancialmente 


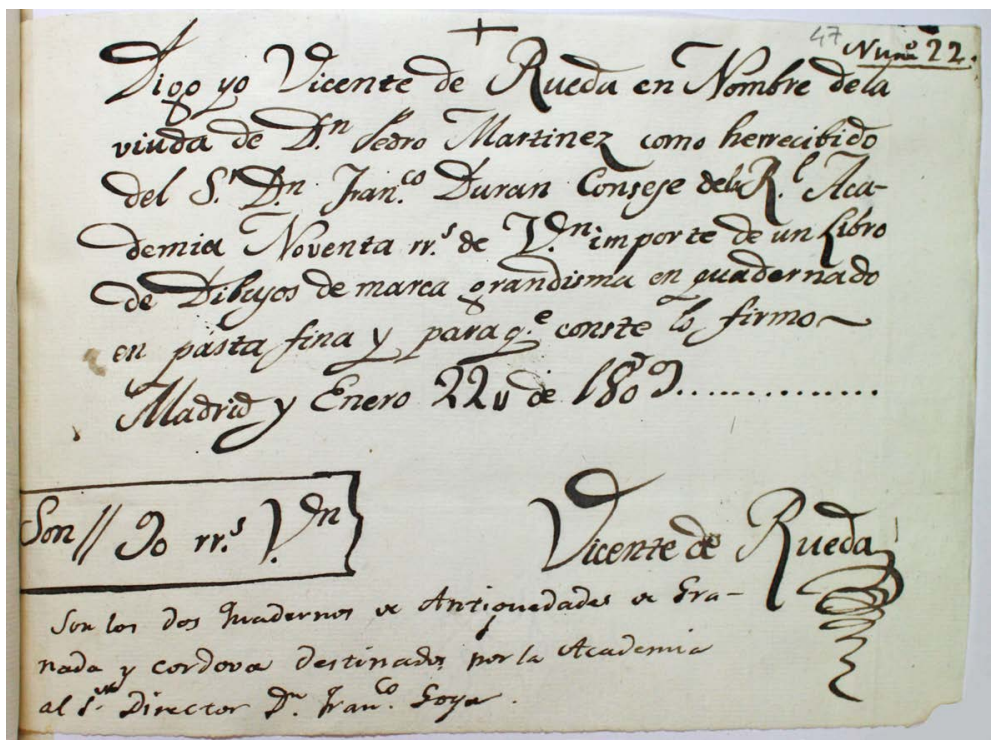

en función del encuadernador. Por ejemplo la Academia pagaba más al taller de Sancha que a otros encuadernadores menos conocidos, como es el caso de Pedro Martínez, por el mismo tipo de obras y con acabados similares.

Para finalizar, observamos la relación del encuadernador Vicente de Rueda con la familia de Pedro Martínez. Vicente fue uno de los encuadernadores que más trabajaron para la Academia. En los libros de cuentas hemos localizado apuntes desde el 22 de enero de 1809 (Figura 12). El primero de ellos se refiere al pago de un volumen, encuadernado en pasta fina, de las Antigüedades Árabes de Granada y Córdoba, en el que el encuadernador actúa en nombre de la viuda de Pedro Martínez, muerto entre los meses de marzo de 1808 y enero de 1809 , siendo posible que Vicente de Rueda se hiciera cargo del taller de Pedro Martínez. El último libramiento de Vicente de Rueda lo encontramos el 20 de julio de 1826 por la encuadernación de cincuenta Geometrías de dibujantes en rústica y doce tomos de los Estatutos de la Academia en pasta. Esto nos hace pensar que Vicente de Rueda ya trabajaba como oficial en el taller de Pedro Martínez, y que a su muerte se hiciera cargo del taller junto a su viuda.

No obstante, seguimos investigando en la relación con otros encuadernadores, incluso sobre los trabajos realizados por este encuadernador en otras Reales Academias, la comparativa de encargos y tipos de encuadernaciones, entre otros, lo que nos podrá ofrecer una visión más global, no solo de los trabajos realizados para esta Real Academia, sino también con otros encuadernadores de la misma época.
Figura 12. Sig. 251/2, recibo no 22, p. $47-1809$ 


\section{Q Referencias bibliográficas}

»Buonocore, Domingo. 1976. Diccionario de Bibliotecología. Buenos Aires: Marymar.

»Capela Martínez, Miguel. 1963. Las artes gráficas de Madrid en el siglo XVIII. En La industria en Madrid: ensayo histórico crítico de la fabricación y la artesanía madrileñas: siglos XVIII al XIX desde 1701 a 1912: la industria en Madrid en el siglo XVIII. Madrid: Artes Gráficas y Ediciones. p. 121-155.

»Carrión Gútiez, Manuel. 1994. La encuadernación española. En Historia ilustrada del libro español: De los incunables al siglo XVIII. Madrid: Pirámide. p. 395-446.

»Castañeda y Alcover, Vicente. 1958. Ensayo de un diccionario biográfico de encuadernadores españoles. Madrid: Maestre.

"Cavestany, Julio. 1927. Las industrias artísticas madrileñas en la exposición de El Antiguo Madrid 1926-1927. Madrid: Gráficas Reunidas.

»Enciclopedia de la encuadernación. 1998. Dirección José Bonifacio Bermejo Martín. Madrid: Ollero y Ramos.

"Flores Hernández, Yohana Yessica y Antonio Carpallo Bautista. 2017. Los encuadernadores de la Real Academia de Bellas Artes de San Fernando. En RUIDERA, Revista de Unidades de Información. No. 12, 255-263.

"Flores Hernández, Yohana Yessica; Antonio Carpallo Bautista y Esther Burgos Bordonau. 2018. El taller de Sancha en la Real Academia de Bellas Artes de San Fernando. En Titivillus. No. 4, 39-62.

» López Castán, Ángel. 1986. La encuadernación madrileña y la comunidad de mercaderes y encuadernadores de libros de la Corte en el siglo XVIII. En Villa de Madrid. Vol. XXIV, no. 89-90, 41-63.

»López Serrano, Matilde. 1937. La encuadernación en Madrid en la primera mitad del siglo XVIII. En Archivo Español de Arte y Arqueología. No. 37, 1-13.

»López Serrano, Matilde. 1940. La encuadernación madrileña en la época de Fernando VI. En Archivo Español de Arte. No. 40, 27-38.

»López Serrano, Matilde. 1945a. La encuadernación española del siglo XVIII. En Gráficas. No. 17, 4-5, 28.

"López Serrano, Matilde. 1945b. La encuadernación madrileña durante el reinado de Carlos III. En Archivo Español de Arte. No. 67, 1-16.

»López Serrano, Matilde. 1945c. El encuadernador Gabriel Gómez Martín. En Revista de Bibliografía Nacional. Vol. VI, 51-72.

"López Serrano, Matilde. 1946a. Antonio de Sancha, encuadernador madrileño. En Revista de Bibliotecas, Archivos y Museos Municipales. No. 54, 269-307.

»López Serrano, Matilde. 1946b. Una tormenta doméstica en la familia Sancha. En Revista de Bibliografía Nacional. Vol. VII, 391-399.

»López Serrano, Matilde. 1950. La encuadernación madrileña en la época de Carlos IV. En Archivo Español de Arte. No. 90, 115-131. 
"López Serrano, Matilde. 1975. Gabriel de Sancha: editor, impresor y encuadernador madrileño (1746-1820). Madrid: Ayuntamiento. Instituto de Estudios Madrileños.

»Vélez Celemín, Antonio. 2012. El marmoleado: del papel de guardas a la obra de arte. Madrid: Ollero y Ramos. 
